minor parent concerning the child//Naukapark. 2018.

№ 5 (66). Page 80-82.]

УДК - 347

ГРНТИ - 10.27 .65

12.00.03 - гражданское право; предпринимательское право; семейное право; международное частное право

О НЕКОТОРЫХ СЛУЧАЯХ ГРАЖДАНСКО-ПРАВОВОЙ ОТВЕТСТВЕННОСТИ ПРИ КАТАСТРОФЕ НА ВОЗДУШНОМ ТРАНСПОРТЕ

DOI: $\frac{10.31618 / \text { ESU.2413-9335.2020.5.72.650 }}{\text { Махиборода Максим Николаевич, }}$
кандидат юридческих наук,
доцент Института Академии ФСИН России
по кафедре гражданского права и проиесса
(390000, г. Рязань, ул. Сенная, д. 1),

\title{
CIVIL LIABILITY IN THE FIELD OF TRANSPORT OBLIGATIONS IN THE CONTEXT OF A CORONAVIRUS PANDEMIC
}

\author{
Makhiboroda Maksim Nikolaevich, \\ PhD in law, \\ associate Professor of the Institute of the Academy of FSIN of Russia \\ Department of civil law and procedure
}

\begin{abstract}
АННОТАЦИЯ
Статья посвящена отдельным часто возникающим случаям гражданско-правовой ответственности на воздушном транспорте при авиакатастрофе. Анализируются нормы воздушного законодательства как отечественные, так и зарубежные. Автором даются предложения по внесению изменений в законодательство Российской Федерации.

\section{ANNOTATION}

The article is devoted to some frequently occurring cases of civil liability in air transport in the event of a plane crash. The article analyzes the norms of air legislation both domestic and foreign. The author makes suggestions on amendments to the legislation of the Russian Federation.

Ключевые слова: гражданско-правовая ответственность, воздушное законодательство, транспортные обязательства, авиакатастрофа.

Key words: civil liability, air legislation, transport obligations, plane crash.

Развитие воздушного транспорта опережает действующую правовую базу, на основе которой происходит законодательное регулирование правоотношений в данной сфере. Необходимо в кратчайшие сроки обратить внимание на совершенствование отдельных норм права в сфере использования воздушного транспорта гражданской авиации.

Именно эта отрасль заставляет по-иному взглянуть на вопросы, касающиеся гражданскоправовой ответственности, рассмотреть проблему правового обеспечения удовлетворения потребностей граждан в услугах с позиции гражданского права как одной из ведущих отраслей права. Для обеспечения должного уровня безопасности полетов имеет значение состояние законодательной базы и правоприменительная практика.

Сложилась крайне неблагополучная ситуация с обеспечением безопасности в сфере воздушных перевозок. Эта проблема носит комплексный характер и напрямую связана с общим состоянием авиатранспорта, который, в свою очередь, находится в сложных условиях выживания.

процессом обеспечения безопасности полетов, нарушено взаимодействие участников авиатранспортного процесса, отсутствуют меры ответственности за состоянием дел.

Одной из основных причин ухудшения состояния безопасности полетов является недостаточная реализация мероприятий по результатам расследования авиационных происшествий и инцидентов, отсутствие контроля за выполнением рекомендаций и мероприятий, что приводит к повторению происшествий по одним и тем же причинам.

Если, несмотря на хорошие технические характеристики самолетов и четкую работу диспетчеров, катастрофа все же произошла, только грамотное поведение пассажиров, профессионализм летного состава и сотрудников всех подразделений Всероссийской службы медицины катастроф могут привести к благоприятному исходу.

Ситуация, сложившаяся в сфере безопасности полетов на воздушном транспорте, заставила ученых и специалистов различных отраслей знаний, таких как экономика, социология,
\end{abstract} Отсутствует единый комплекс мер по управлению 
медицина, юриспруденция и других, заниматься исследованием причин авиакатастроф.

На воздушном транспорте при перевозке чаще всего возникают следующие ситуации: утрата, недостача или повреждение (порча) перевозчиком багажа или груза; совершение акта терроризма на воздушном судне, который впоследствии может привести к катастрофе; причинение имущественного вреда третьим лицам в случае авиакатастрофы; катастрофа, произошедшая зарубежом или с участием иностранных граждан на территории РФ и другие, - в результате которых наступает гражданско-правовая ответственность $[1$, c. $56-81]$.

Воздушный кодекс Российской Федерации [2] (далее - ВК РФ) предусматривает, что ответственность за утрату, недостачу или повреждение (порчу) багажа или груза несет перевозчик после принятия их к воздушной перевозке и до выдачи грузополучателю или до передачи их согласно установленным правилам другому гражданину или юридическому лицу в случае, если не докажет, что им были приняты все необходимые меры по предотвращению причинения вреда или такие меры невозможно было принять (п. 1 ст. 118 ВК РФ). Перевозчик также несет ответственность за сохранность ручной клади, если не докажет, что утрата, недостача или повреждение (порча) ручной клади произошли вследствие обстоятельств, которые перевозчик не мог предотвратить и устранение которых от него не зависело, либо умысла пассажира (п. 2 ст. 118 ВК РФ). При причинении вреда имуществу пассажира в случае авиакатастрофы также наступает гражданско-правовая ответственность в соответствии с законодательством РФ.

В соответствии с п. 3 ст. 118 ВК РФ перевозчик может быть освобожден от ответственности за утрату, недостачу или повреждение (порчу) багажа или груза, если докажет, что это произошло не во время воздушной перевозки.

Из текста п. 3 ст. 118 ВК РФ можно предположить, что, если перевозчик докажет, что утрата, недостача, повреждение (порча) груза не возникли в результате совершенных им умышленных действий (бездействия), то данное обстоятельство может освободить его от ответственности. Это не может являться основанием освобождения от ответственности за несохранность перевозимого груза, так как в соответствии с гражданским законодательством РФ от перевозчика требуется принятие всех необходимых мер для обеспечения его сохранности.

Основания ответственности перевозчика за утрату, недостачу или повреждение (порчу) багажа, груза и ручной клади при международных воздушных перевозках определяются в соответствии с международными договорами Российской Федерации (п. 4 ст. 118 ВК РФ).

Слабыми сторонами современного российского законодательства являются качество и юридическая техника принимаемых нормативных актов. Транспортные уставы и кодексы $[2,3,4,5,6$, 7] часто вступают в противоречие с Гражданским кодексом Российской Федерации [8] (далее - ГК РФ), они перегружены отсылочными нормами к правилам перевозок и иным подзаконным нормативным актам [9, с. 14].

В связи с этим, на основе п. 1 ст. 796 ГК РФ, текст п. 3 ст. 118 ВК РФ следовало бы сформулировать иначе: «Перевозчик несет ответственность за утрату, недостачу или повреждение (порчу) багажа или груза, если не докажет, что утрата, недостача или повреждение (порча) этих вещей произошли вследствие обстоятельств, которые перевозчик не мог предотвратить и устранение которых от него не зависело, либо это произошло не во время воздушной перевозки».

Необходимо отметить особенности договоров хранения и охраны, которые позволяют определить правовую природу отношений между пассажиром воздушного судна и перевозчиком. Имеется в виду, что на перевозчика возлагается ответственность за сохранность находящихся при пассажире вещей. В этом случае договор перевозки пассажиров включает элементы именно охраны вещей, а не их хранения. Это обстоятельство учитывается при определении оснований и размера ответственности перевозчика [10, с. 170].

В случае авиакатастрофы в соответствии со ст. 119 ВК РФ перевозчик за утрату, недостачу или повреждение (порчу) багажа, груза, а также ручной клади перевозчик несет ответственность в следующих размерах:

1) за утрату, недостачу или повреждение (порчу) багажа, груза, принятых к воздушной перевозке с объявлением ценности, - в размере объявленной ценности. За воздушную перевозку багажа или груза с объявленной ценностью с грузоотправителя или грузополучателя взимается дополнительная плата, размер которой устанавливается договором воздушной перевозки багажа или договором воздушной перевозки груза;

2) за утрату, недостачу или повреждение (порчу) багажа, груза, принятых к воздушной перевозке без объявления ценности, - в размере их стоимости, но не более шестисот рублей за килограмм веса багажа или груза;

3) за утрату, недостачу или повреждение (порчу) ручной клади - в размере ее стоимости, а в случае невозможности ее установления - в размере не более чем одиннадцать тысяч рублей.

Стоимость багажа, груза, а также ручной клади определяется исходя из цены, указанной в счете продавца или предусмотренной договором, а при ее отсутствии исходя из средней цены на аналогичный товар, существовавшей в том месте, в котором груз подлежал выдаче, в день добровольного удовлетворения такого требования или в день вынесения судебного решения, если требование добровольно удовлетворено не было.

Отметим, что в данной статье несоответствие нормы специального закона (ВК РФ) императивной норме общего закона (ГК РФ), согласно которой 
перевозчик обязан в случае повреждения (порчи) груза при невозможности восстановления груза возместить его стоимость, а также возвратить отправителю (получателю) провозную плату не только за недоставленный груз (полностью или в части), но и за поврежденный (испорченный) груз (п. 3 ст. 796 ГК РФ).

Таким образом, необходимо дополнить ст. 119 ВК РФ п. 1.2: «Перевозчик наряду с возмещением установленного размера ответственности, вызванного утратой, недостачей или повреждением (порчей) груза или багажа, возвращает отправителю (получателю) провозную плату, взысканную за перевозку утраченного, недостающего, испорченного или поврежденного груза или багажа, если эта плата не входит в стоимость груза».

При предъявлении требований, в случае нарушения договора воздушной перевозки пассажира, груза, почты ВК РФ предусматривается составление коммерческого акта, удостоверяющего обстоятельства, которые могут служить основанием для имущественной ответственности. Требования могут быть предъявлены в аэропорте пункта отправления или пункта назначения по усмотрению заявителя.

Определение порядка обращения с претензией к перевозчику ГК РФ относит к компетенции соответствующих транспортных уставов и кодексов. В Воздушном кодексе РФ это определено ст.ст. 122-127.

В случае недостачи или повреждения (порчи) груза претензия пассажира должна быть заявлена в письменной форме с приложением к ней коммерческого акта. ВК РФ лишил коммерческий акт правоустанавливающего значения. Его отсутствие не лишает пассажира, грузоотправителя и грузополучателя права на предъявление претензии (п. 5 ст. 124 ВК РФ). Однако, в случае недостачи, повреждения (порчи) груза наличие коммерческого акта для предъявления претензии необходимо, если у грузополучателя отсутствует грузовая накладная (пп. 1 п. 1 ст. 125 ВК РФ).

К претензии должен быть приложен также документ, удостоверяющий количество и стоимость отправленного груза. Отсутствие последнего не лишает права на обращение с претензией, но может затруднить принятие перевозчиком решения об удовлетворении претензии [10, с. 174-175].

В случае нарушения договора воздушной перевозки пассажира, груза или почты ВК РФ в ст. 125 четко определяет круг лиц, имеющих право на предъявление требований:

1) пассажир или управомоченное им лицо при предъявлении багажной квитанции или коммерческого акта - при утрате, недостаче или повреждении (порче) багажа, а также просрочке его доставки;

2) пассажир - при прекращении договора по инициативе перевозчика.

Право на предъявление претензии и иска к перевозчику имеют следующие лица в случае:
1) утраты груза - грузополучатель при предъявлении грузовой накладной, выданной перевозчиком грузоотправителю, с отметкой аэропорта пункта назначения о прибытии (неприбытии) груза, а при невозможности предъявления такой накладной документа об оплате стоимости груза и справки перевозчика об отправке груза с отметкой аэропорта пункта назначения о прибытии (неприбытии) груза;

2) недостачи или повреждения (порчи) груза грузополучатель при предъявлении грузовой накладной или коммерческого акта;

3) просрочки доставки груза - грузополучатель при предъявлении грузовой накладной;

4) утраты, недостачи или повреждения (порчи) почты, а также просрочки ее доставки организация почтовой связи пункта назначения почты;

5) страховщик при предъявлении соответствующих перевозочных документов, а также документов, подтверждающих факты заключения договора страхования и выплаты страхового возмещения [11, с. 82-113].

Претензия к перевозчику при внутренних воздушных перевозках может быть предъявлена в течение 6 месяцев. Указанный срок в соответствии со ст. 126 ВК РФ исчисляется следующим образом:

- о возмещении вреда в случае недостачи или повреждения (порчи) груза или почты, а также в случае просрочки их доставки - со дня, следующего за днем выдачи груза, а в отношении почты - с даты составления коммерческого акта;

- о возмещении вреда в случае утраты груза через 10 дней по истечении срока доставки;

- о возмещении вреда в случае утраты почты по истечении срока доставки;

- о возмещении вреда во всех остальных случаях - со дня наступления события, послужившего основанием для предъявления претензии.

В случае недостачи или повреждения (порчи) багажа, груза при международных воздушных перевозках лицо, управомоченное на получение багажа, груза, при обнаружении таких недостачи или повреждения (порчи) должно предъявить претензию к перевозчику в письменной форме или в форме подписанного электронной подписью электронного документа с момента обнаружения таких недостачи или повреждения (порчи), но не позднее семи дней со дня получения багажа и четырнадцати дней со дня получения груза. В случае просрочки доставки багажа, груза претензия должна быть предъявлена к перевозчику в течение двадцати одного дня со дня передачи багажа, груза в распоряжение лица, управомоченного на их получение (ст. 127 ВК РФ).

Перевозчик обязан в течение тридцати дней со дня поступления претензии рассмотреть ее и в письменной форме или в форме подписанного электронной подписью электронного документа уведомить лицо, предъявившее претензию, об удовлетворении или отклонении претензии. 
Перевозчик обязан в течение тридцати дней со дня поступления претензии рассмотреть ее и в письменной форме или в форме подписанного электронной подписью электронного документа уведомить лицо, предъявившее претензию, об удовлетворении или отклонении претензии (ст. 128 ВК РФ).

Сравним исчисление срока исковой давности в других транспортных кодексах и уставах. Например, в Кодексе торгового мореплавания Российской Федерации [3] (далее - КТМ РФ) согласно ст. 408 КТМ РФ годичный срок исковой давности исчисляется по следующим требованиям:

- возмещения ущерба за утрату груза - по истечении тридцати дней со дня, в который груз должен быть выдан, при перевозке в смешанном сообщении - по истечении четырех месяцев со дня приема груза для перевозки;

- возмещения ущерба за повреждение груза, просрочки его доставки и возврата перебора или взыскания недобора провозных платежей - со дня выдачи груза и, если груз не был выдан, - со дня, в который он должен быть выдан;

- возмещения убытков за неподачу судна или подачу его с опозданием, платы за простой судна и досрочную погрузку или выгрузку груза - со дня окончания месяца, следующего за тем, в котором началась или должна была начаться перевозка груза;

- в остальных случаях - со дня наступления события, послужившего основанием для предъявления требования.

Стоит отметить, что по КТМ РФ вина перевозчика, его работников или агентов, действовавших в пределах своих обязанностей (полномочий), наступает только в тех случаях, если утрата или повреждение каютного багажа произошли в результате кораблекрушения, столкновения, посадки судна на мель, взрыва или пожара на судне. В остальных случаях обязанность доказывания перекладывается на истца [12, с. 29]. По нашему мнению, определение вины в таком случае аналогичным образом может осуществляться и при воздушных перевозках (как международных, так и внутренних).

В соответствии с Уставом железнодорожного транспорта Российской Федерации [4] претензии к перевозчику предъявляются в течение 6 месяцев; претензии в отношении штрафов и пеней - в течение 45 дней.

Отметим, что исчисление претензионных сроков исковой давности в случае утраты, недостачи или повреждении (порчи) перевозчиком багажа или груза в транспортных кодексах и уставах схожи и не имеют особых расхождений.

Одной из самых важных на сегодняшний день проблем во всем мире является противодействие терроризму. В отдельных случаях неправомерное завладение во время полета воздушным судном другими лицами может привести к авиакатастрофе. При отсутствии вины владелец освобождается от ответственности при выбытии источника повышенной опасности из его обладания в результате противоправных действий третьих лиц (п. 2 ст. 1079 ГК РФ). Ответственность за вред в этом случае будут нести лица, противоправно завладевшие воздушным судном. При наличии вины владельца источника повышенной опасности в противоправном изъятии этого источника из его обладания ответственность может быть возложена как на владельца, так и на лицо, противоправно завладевшее источником повышенной опасности [13, с. 161-165].

Пострадавшие от терроризма люди не должны оставаться один на один со своей бедой. Государство возложило на себя обязанность оказывать материальную, моральную, социальнопсихологическую, медицинскую и иные виды помощи, а также компенсацию вреда, причиненного жертвам террора. И оно обязано делать все возможное в этом направлении [14, с. 44]. Федеральный закон «О противодействии терроризму» [15] регулирует данные правоотношения.

Денежная компенсация имеет целью вызвать положительные эмоции, максимально сгладив негативные изменения в психической сфере, обусловленные перенесенными страданиями. Конечно, денежная компенсация не возместит утраты человеческой жизни, повреждения здоровья, не снимет нравственные страдания от пережитого страха, стыда, унижения и иных переживаний, но, поскольку деньги являются универсальным имущественным эквивалентом, то это позволит хотя бы временно сменить обстановку, сгладить страдания, смягчить переживания, уменьшить их претерпевания или снизить остроту $[16$, с. 8$]$.

Проблема, которая неизбежно возникает в связи с совершением террористических преступлений, заключается в защите потерпевших от их последствий, в частности - в компенсации за причиненный им материальный вред. Для того чтобы определить размер компенсации, необходимо знать, в первую очередь, объем и размер вреда, причиненного пострадавшему от террористического акта.

Материальный и моральный вред, причиняемый террористами, ставит вопрос о его возмещении, однако он осложняется тем, что непосредственные причинители вреда в большинстве случаев погибают, но даже если остаются в живых - материального возмещения от них добиться невозможно.

В свою очередь стоит отметить, что Российская Федерация при совершении террористических актов от лица государства самостоятельно выплачивает разовую компенсацию пострадавшим. Эта сумма, конечно, мала с потерями понесенными людьми. Но, учитывая тот факт, что не всегда можно найти виновного, либо он просто погибает, этот способ остается единственной возможностью для компенсации вреда. Обратим внимание на то, что в некоторых странах предусматривается пожизненная компенсация. 
В России, в условиях отсутствия единого порядка исчисления и выплат пострадавшим от терактов, была практика принятия нормативных документов по каждому отдельному случаю.

В настоящее время компенсация в случае авиакатастрофы вследствие террористического акта производится из средств федерального бюджета в размере, предусмотренном воздушным законодательством и Правительством РФ. Положительный опыт в области защиты жертв террористических актов, способы и механизмы защиты прав потерпевших, применяемые в развитых странах, крайне важны для России и, более того, ложатся в основу при разработке новых законов.

Основным способом возмещения гражданам за вред, причиненный террористическими актами, во всем мире, в том числе и в России, на сегодняшний день остается денежная компенсация.

На практике на воздушном транспорте при перевозке встречаются происшествия, которые связаны с причинением имущественного вреда третьим лицам. Согласно п. 2 ст. 130 ВК РФ в этом случае, владелец воздушного судна несет ответственность в размере, предусмотренном гражданским законодательством РФ, если иное не предусмотрено международным договором РФ.

Отметим, что согласно ВК РФ, ответственность за вред, причиненный жизни или здоровью пассажира при воздушной перевозке в случае авиакатастрофы, произошедшей зарубежом или с участием иностранных граждан на территории Российской Федерации, определяется не только общими правилами Гражданского кодекса РФ, если законом или договором воздушной перевозки не предусмотрен более высокий размер ответственности, но и международными договорами.

При международных воздушных перевозках за утрату, недостачу или повреждение (порчу) багажа, груза, а также ручной клади при международных воздушных перевозках перевозчик несет ответственность в соответствии с международными договорами Российской Федерации (п. 3 ст. 119 ВК РФ).

Например, Монреальская конвенция [17] установила неограниченную ответственность. Она ввела двухуровневую систему ответственности. Первый уровень - объективная ответственность в размере до 100 тысяч специальных прав заимствования (далее - СПЗ) (около 140 тысяч долларов США) независимо от вины перевозчика.

Второй уровень основывается на презумпции вины перевозчика и не предусматривает ограничения ответственности. Ответственность перевозчика за вред в случае смерти или телесного повреждения возникает только при условии наступления смерти или телесного повреждения на борту воздушного судна или во время любых операций по посадке или высадке. В отношении такого вреда компенсация не превышает 100 тысяч СПЗ на каждого пассажира, и перевозчик не может исключать или ограничивать свою ответственность. В случае превышения размера вреда на каждого пассажира 100 тысяч СПЗ перевозчик не несет ответственности за вред в случае смерти или телесного повреждения пассажира, если он докажет, что такой вред не был причинен небрежностью или другим неправильным действием либо бездействием перевозчика или его агентов. С другой стороны, уполномоченное лицо, которое считает, что вред, причиненный по вине перевозчика, превышает 100 тысяч СПЗ, должен доказать его вину [18, с. 55-56].

На сегодняшний день состояние системы транспортного законодательства России далеко от идеального. Несмотря на появление новых правовых институтов и конструкций оно все еще несет на себе отпечаток экономических отношений, существовавших в прежней системе хозяйствования. Очевидно, что это является фактором не только снижающим эффективность транспортной деятельности, но и в определенном смысле тормозящим развитие всего транспортного комплекса.

Таким образом, гражданско-правовая ответственность на воздушном транспорте при авиакатастрофе в соответствии с законодательством РФ и международными договорами РФ наступает: при утрате, недостаче или повреждении (порче) багажа или груза; совершении акта терроризма на воздушном судне во время полета; причинении имущественного вреда третьим лицам; в случае катастрофы, произошедшей зарубежом или с участием иностранных граждан на территории РФ. Существуют и другие случаи, часто возникающие на воздушном транспорте, при которых гражданско-правовая ответственность может наступить, но мы рассмотрели наиболее типичные.

\section{Список литературы:}

1. Блинкова Е.В., Еремина Ю.О., Махиборода M.Н. Гражданско-правовая ответственность и медицинская помощь в случае авиакатастрофы: Монография / Под общ. ред. д.ю.н., профессора Е.В. Блинковой. - Рязань: ООО «Копи Принт», 2009. - 151 с.

2. Воздушный кодекс Российской Федерации от 19 марта 1997 г. № 60-Ф3 (в ред. от 18.02.2020 г.) // Собрание законодательства РФ. 1997. № 12. Ст. 1383.

3. Кодекс торгового мореплавания Российской Федерации от 30 апреля 1999 г. № 81 Ф3 (в ред. от 01.03.2020 г.) // Собрание законодательства РФ. 1999. № 18. Ст. 2207.

4. Федеральный закон от 10 января 2003 г. № 18-Ф3 «Устав железнодорожного транспорта Российской Федерации» (в ред. от 02.08.2019 г.) // Собрание законодательства РФ. 2003. № 2. Ст. 170.

5. Федеральный закон от 08.11.2007 г. № 259Ф3 (в ред. от 30.10.2018 г.) «Устав автомобильного транспорта и городского наземного электрического транспорта» // Собрание законодательства РФ. 2007. № 46. Ст. 5555.

6. Кодекс внутреннего водного транспорта Российской Федерации от 07.03.2001 г. № 24-Ф3 (в 
ред. от 02.08.2019 г.) // Собрание законодательства РФ. 2001. № 11. Ст. 1001.

7. Федеральный закон от 29.12.2017 г. № 442Ф3 «О внеуличном транспорте и о внесении изменений в отдельные законодательные акты Российской Федерации» // Собрание законодательства РФ. 2018. № 1 (Часть I). Ст. 26.

8. Гражданский кодекс Российской Федерации часть вторая от 26 января 1996 г. № 14 Ф3 (в ред. от 18.03.2019 г., с изм. от 03.07.2019 г.) // Собрание законодательства РФ. 1996. № 5. Ст. 410.

9. Молчанов В.В. Нормативно-правовое регулирование воздушных перевозок // Законодательство. № 4. 2006. С. 9-15.

10. Троицкая О.Н., Симаненко А.М. Комментарий к Воздушному кодексу РФ. М.: Волтерс Клувер, 2007. - 191 с.

11. Ефремов Е.А. Договор воздушной перевозки: дис. ... канд. юрид. наук. Волгоград, 2006. - 191 c.

12. Остроумов Н.Н. Об ответственности воздушного перевозчика за несохранность груза и багажа // Государство и право. 2005. № 2. С. 26-35.
13. Солдатенко О.M. Гражданско-правовое регулирование ответственности за вред, причиненный источником повышенной опасности: дис. ... канд. юрид. наук. Саратов, 2002. - 186 с.

14. Трунов И.Л. Борьба с терроризмом: необходима адекватная компенсация вреда его жертвам // Журнал российского права. 2004. № 5. С. 44-50.

15. Федеральный закон «О противодействии терроризму» от 6 марта 2006 г. № 35-Ф3 (в ред. от 18.03.2020 г.) // Собрание законодательства РФ. 2006. № 11. Ст. 1146.

16. Трунов И.Л. Возмещение вреда, причиненного в результате террористического акта // Профессионал. 2003. № 1 (51). С. 8-10.

17. Конвенция для унификации некоторых правил международных воздушных перевозок (Заключена в г. Монреале 28.05.1999 г.) // Собрание законодательства РФ. 2017. № 37.

18. Бордунов В.Д. Международное воздушное право: Учебное пособие. М.: НОУ ВКШ «Авиабизнес»; «Научная книга», 2006. $464 \mathrm{c}$.

УДК 340.14

ГРНТИ 10.07.45

\title{
ПРАВО ИСКУССТВЕННОГО ИНТЕЛЛЕКТА КАК НОВАЯ СФЕРА ПРАВОВОГО РЕГУЛИРОВАНИЯ ИЛИ НОВАЯ ОТРАСЛЬ ПРАВА
}

\author{
Мишина Наталья Вячеславовна \\ Доктор политических наук, \\ профессор кафедры теории и истории государства и права, \\ магистр техники и технологий \\ АНОВО «МОСКОВСКИЙ МЕЖДУНАРОДНЫЙ УНИВЕРСИТЕТ», \\ г. Москва, Ленинградский пр., д. 17.
}

\section{ARTIFICIAL INTELLIGENCE LAW AS A NEW AREA OF LEGAL REGULATION OR A NEW BRANCH OF LAW}

\section{АННОТАЦИЯ}

В статье обосновывается необходимость правового регулирования в сфере функционирования искусственного интеллекта и формирования новой отрасли права - права искусственного интеллекта. На основе проведённого исследования с применением методов исторической ретроспективы, анализа и синтеза, прогнозирования, систематизации и аналогии, автором сделан вывод, что правовое регулирование должно быть последовательным, системным и перспективным, способным предотвратить возможные негативные последствия от деятельности искусственного интеллекта. Новая отрасль права призвана обеспечить ликвидацию правовых пробелов в сфере искусственного интеллекта, а также устранить барьеры для научно-технического развития в области создания, функционирования и совершенствования систем искусственного интеллекта.

\section{ABSTRACT}

The article substantiates the need for legal regulation in the field of artificial intelligence and the formation of a new branch of law - the law of artificial intelligence. Based on the research conducted using the methods of historical retrospect, analysis and synthesis, forecasting, systematization and analogy, the author concludes that legal regulation should be consistent, systematic and promising, able to prevent possible negative consequences from the activities of artificial intelligence. The new branch of law is designed to ensure the elimination of legal gaps in the field of artificial intelligence, as well as to eliminate barriers to scientific and technological development in the field of creating, functioning and improving artificial intelligence systems.

Ключевые слова: право искусственного интеллекта, искусственный интеллект, робототехника, отрасль права, робоправо.

Keyword: the right artificial intelligence, artificial intelligence, AI, robotic technology, RT, branch of law, robolow. 